\title{
Digging Deeper: Art Museums in Las Vegas?
}

\author{
Kathryn A. Braun-LaTour, University of Nevada,-Las Vegas \\ Flavia Hendler, University of Nevada,-Las Vegas \\ Rom Hendler, VP Strategic Marketing at the Venetian
}

Las Vegas has been called the "city of reinvention" (Douglass and Raento 2003). Part of its more recent reinvention efforts has included the opening of five fine-art venues. However, one of the art museums - the Las Vegas Guggenheim - was shut down in its first year due to low attendance; another, the Bellagio Fine Art Gallery, has seen attendance dwindle (Schemeligian 2004). The question addressed here is whether the museums are bringing the intended intangible benefits to the host resort, or whether the sales and attendance figures represent overall disinterest. More broadly one considers the potential "fit" between sin-city and the high-art cultural world.

The difficulty in addressing these issues is that tourists might not consciously recognize the value they feel about having a worldclass art museum onsite. Within nonprofit research there has been a call for "deeper understanding" of tourists (Thyne 2001) as reflected within the greater interest in new qualitative methodologies (Riley and Love 2000). The Zaltman metaphor elicitation technique, a patented research method, was chosen to investigate this research issue. Many of the world's largest companies (such as Procter \& Gamble) have utilized this method for insight on brand meaning and competitive positioning.

The Zaltman method is based on several assumptions about how the mind works, drawing from diverse fields of clinical psychology, cognitive neuroscience, and sociology. These assumptions drive how the one-on-one interview is structured and data interpreted. The first assumption is that people think in images, not words, and the former are thought to represent both literal and latent meanings. Among other assumptions: consumers use metaphors to represent important dimensions, memory is storybased, and emotion and sensory aspects are as important, if not more so, than "rational" thought (Zaltman 2003).

In the present study, participants were asked to find eight images that represent their thoughts and feelings about the Venetian, the host of the failed Guggenheim Las Vegas and current host of the Guggenheim-Hermitage (henceforth "Guggenheim"). Participants typically spend several hours thinking about the topic when locating the appropriate visual images. Eleven Venetian guests ( 5 male, 6 female) 
representing various ethnic, age and geographic regions were selected (and compensated) for their participation in the study. A small sample size is typical of this type of study (Griffin and Hauser 1993).

The Zaltman interview occurs in a one-on-one manner, where the interviewer acts like a psychoanalyst using images and metaphoric probing to uncover implicit associations. The first-half of the 90-minute interview consisted of having the participant tell "stories" about their pictures. The second half involved more directly probing views of the Guggenheim art museum. The interview ended with participants composing a story involving the Venetian, the Guggenheim, and the city of Las Vegas. The interviews were coded by two researchers trained in the method. Forty-four constructs emerged overall where 12 were common between the Venetian and the Guggenheim (Figure 1). A construct is literally a "construction" used to represent tourists' important thoughts and feelings of how they related to the Venetian's image rather than its more concrete attributes (for example, that it has suites).

Participants felt that the Venetian and the Guggenheim fit well together: the art museum shared similar architecture and was viewed as part of the Venetian's authenticity. The interviewee Cathy (all names disguised) mentioned that it's part of the Venetian's exclusivity: “Because guests are in a position to see these exquisite pieces that you wouldn't be able to see anywhere else unless you specifically traveled to the destination where these treasures are held [the Louvre]. It's a luxury having it available to people." The Guggenheim was seen as part of the opulence of the Venetian, leading to the constructs of cache, culture, sophistication, and "bragging rights." For instance, Gigi said she used it to help justify her choice of a destination: "When I talk to those people who don't like Las Vegas because they've never been here I can tell them it's not just a place to gamble ... [but] where you can have an elegant dinner, visit a museum, look at art both inside and outside the museum". It was also found that the Venetian was critical in making the Guggenheim "fit" Las Vegas-participants did not feel the museum would work elsewhere, as Lori's story segment demonstrates: "The city of Las Vegas would be an older person, retiree, from a different part of the country. An older Italian person would represent the Venetian and a little more reserved person from a major metropolitan city would represent the Guggenheim. The Venetian would be somebody who brings the other two parties together. As sort of the happy, comfortable person who's there, who evokes a feeling of family and everyone being embraced no matter how different they might be..."

The researchers then searched for deep metaphors. These are the home for latent and emerging needs as well as the source of basic perceptual and behavioral predispositions (Zaltman 2003). They are the most fundamental categories of thought and can be the umbrella concept used (in this case) to better position the art museum. One way to identify a deep metaphor is by looking at 
paradoxes. Participants said they like to feel at home and be comfortable, but at the same time are attracted to the luxury and opulence of the Venetian. While they like the excitement and energy of the casino, they also long for the serenity of their rooms and spa areas. While they like the architecture and buildings, they also desire and appreciate the more "natural" aspects of the Venetian. This longing for different extremes represents a "balance" the Venetian guest makes in their mind about their experience at the resort (and overall in Las Vegas). For instance, Robert said about the museum's relationship to balance: "You get a little overwhelmed when you are here [Las Vegas]. It gets a little chaotic so it's nice to have an hour or two to do something that's a little calmer. It's a different kind of time than the casinos or the rest of the hotel".

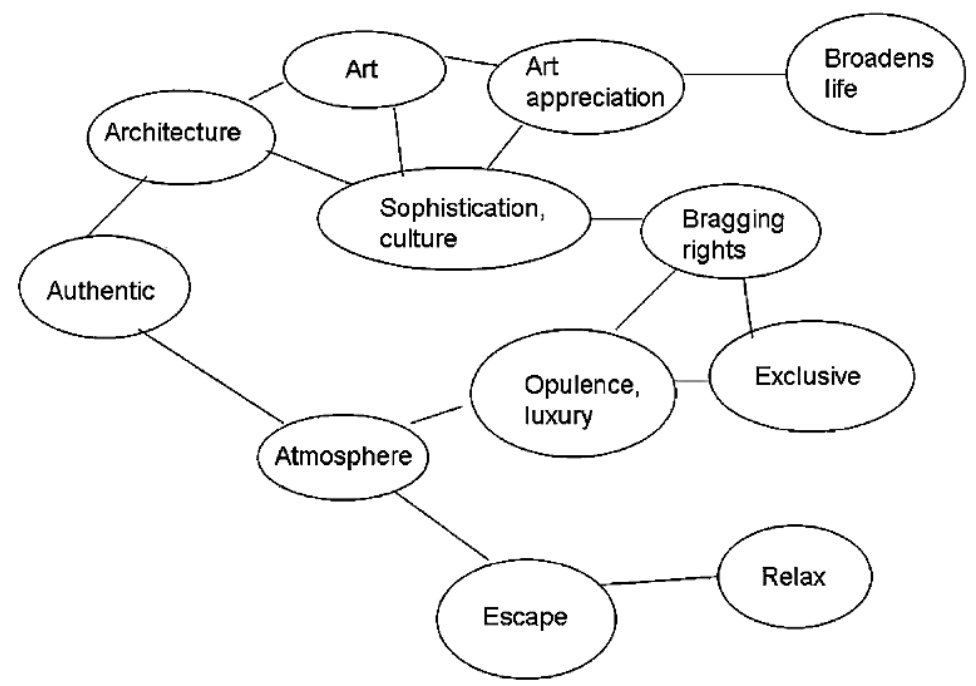

Figure 1. Mental Model of Commonalities between the Venetian and the Guggenheim

The second deep metaphor was transformation, which involves moving from one state to another. The Las Vegas tourist transformation journey begins by "escaping" their day-to-day life. Upon entering Las Vegas, they enter a fantasy land very unlike where they came from. The Venetian offers them their own fantasy, being in a Venice-themed environment. The Venetian itself "transforms" from day to night, from the more casual vacationers shopping in the retail areas during the day with the brighter sky, to the more elegant, sophisticated night scene. Transformation can be both physical (day and night) and psychological, having to do with one's state of mind. Rick says,

In the context of the museum, feeling good is the ability to expand your horizons and be able to experience different expressions of people from a different era, different time, different place. Creativity may or may not be something you directly relate to, but everybody has a bit of a creative streak in them and appreciating art appeals to that particular piece of them. 
This study has several implications. First, the Zaltman method was found to be effective for bringing out more emotional and intangible aspects of tourists' visit. Because photographs are such an integral part of a tourists' experience, future research might employ using those images as part of the interview. Second, the construct map showed that the museum shares (and perhaps is even driving) the exclusive, opulent image associated with the Venetian. Last, the issue remains regarding low attendance at the art museums. Does high art "fit" Las Vegas? Perhaps positioning it on the deep metaphors of balance and transformation would strengthen that fit.

\section{References}

Douglass, W., and P. Raento 2003 The Tradition of Invention: Conceiving Las Vegas. Annals of Tourism Research 31:7-23.

Griffin, A., and J. Hauser 1993 The Voice of the Customer. Marketing Science Institute 12 (1):1-27.

Riley, R., and L. Love 2000 The State of Qualitative Tourism Research. Annals of Tourism Research 27:164-187.

Schemeligian, B. 2004 A Work in Progress. Casino Journal 17 (2):22.

Thyne, M. 2001 The Importance of Values Research for Non-Profit Organisations: The Values' Based Motivations of Museum Visitors. International Journal of Nonprofit and Voluntary Sector Marketing 6:116-130.

Zaltman, G. 2003 How Customers Think. Cambridge: Harvard Business School Press. 